\title{
Tomar el derecho
}

Take the Law

\author{
Romina Lerussi*
}

Resumen: En el marco de la discusión acerca de la relación entre el derecho y la enseñanza en la actualidad, la autora introduce tres reflexiones tangenciales: en primer lugar, el derecho en la generación de la desigualdad; en segundo, la enseñanza jurídica de la jerarquía; finalmente, la arquitectura legal androcéntrica.

Palabras Clave: derecho, enseñanza, desigualdad, jerarquía, androcentrismo, libertad.

Abstract: Within the framework of the discussion on the relationship between law and education today, the author introduces three tangential reflections: firstly, law in the generation of inequality; secondly, the legal teaching of hierarchy; and finally, the androcentric legal architecture.

Keywords: law, education, inequality, hierarchy, androcentrism, freedom. 


\section{Introducción}

La médula de la discusión que presento se sitúa en la relación entre el derecho y la enseñanza en la actualidad. Quizás las preguntas de fondo sean para qué, cómo y a quienes sirve el derecho. Quizás lo que conecta a quienes aquí nos vemos sea una sensibilidad en cuanto a maneras de vivir la política (jurídica) y que arriesgo en nombre propio: la de la libertad común, es decir, con otros y con otras en comunidad de iguales.

E1 texto principal de Josefa Dolores Ruiz Resa objeto de conversación y titulado La enseñanza del derecho en la economía del aprendizaje, propone claves acerca de las actuales prácticas educativas y profesionales en el derecho, en el contexto de las nuevas tecnologías y de prerrogativas internacionales orientadas al mercado de competencias y de empleabilidad. Suplementan al principal dos comentarios extensos. El primero de Mauro Benente, La enseñanza del derecho en la racionalidad sobredeterminada de la economía del aprendizaje, quien en los ecos de la sobredeterminación instala una esperanza: la de la resistencia. El segundo de Malena Costa Wegsman bajo el nombre Formación jurídica $y$ androcentrismo, quien clava en el corazón de esta discusión la conformación androcéntrica del derecho en su base fundacional. Finalmente cierra este espiral abierto por definición, una réplica de Ruiz Resa desde, en sus términos, un pesimismo situado y encarnado en el que se asoman algunas luces.

Siguiendo el tono de estas provocaciones introduzco muy brevemente tres reflexiones tangenciales a partir de inspiraciones reconocibles. En primer lugar, el derecho en la generación de la desigualdad; en segundo, la enseñanza jurídica de la jerarquía; finalmente, la arquitectura legal andrócentrica.

\section{Desigualdad}

Preguntarse por la relación entre el capitalismo, la mercantilización del conocimiento, las tecnologías digitalizadas de la información y la 
comunicación y las nuevas servidumbres cognitivas en la enseñanza del derecho, es básicamente ubicarnos en las funciones del derecho en la actual organización de la desigualdad. Y con esto no estamos diciendo nada nuevo. E1 derecho siempre ha sido una tecnología social más o menos compleja, más o menos sistematizada, más o menos efectiva situada en el centro de la economía política disciplinaria de las comunidades humanas en contextos de diversa desigualdad. Sí podemos reconocer en el derecho una cierta singularidad de época en formas y efectos que hay quienes denominan autonomía relativa. Con todo, leemos en los textos a continuación y en torno al sintagma que propone Ruiz Reza, $\mathrm{La}$ enseñanza del derecho en la economía del aprendizaje, reflexiones acerca de la progresiva contracción de la legalidad estatal (vuelve la crítica marxista), la centralidad del contrato y de la responsabilidad personal (vuelve la crítica al sujeto moderno), el eje en los emprendedores y el individuo autónomo (vuelve la crítica a la universalidad igualitaria abstracta y neutral). Y no es casualidad que al mismo tiempo estemos hablando de nuevas formas de esclavitud y servidumbre. Tecnologías de la información y la comunicación digitalizadas, bajo el control de empresas multinacionales que venden y compran conocimientos, en sistemas regulados por grupo económicos y normas jurídicas transnacionales que enriquecen y legitiman a personas y familias singulares. Un esquema que se da en contextos de altísima desigualdad, progresiva informalidad en el trabajo remunerado, explotación a todo nivel (en el trabajo no remunerado, exponencialmente), desocupación, fugas al derecho laboral así como desiertos en esta materia, todo lo cual ya sabemos qué significa. Y entonces bien podríamos preguntarnos ¿quiénes son hoy los afectados, los vulnerables? Los mismos seres humanos de siempre (vistos o no vistos como tales): más del 80 por ciento de la población mundial en sistemas ensamblados de desigualdades (de clases, razas, etnias, sexo - genéricas, de estatus migratorio, etcétera). No son novedades, sino reminiscencias actualizadas, insoportables y urgentes.

En este panorama y en la singularidad de la reflexión acerca del derecho y la enseñanza, digo dos cosas. Una, la obligación de recordar todos los días la falsa autonomía del derecho respecto del debate económico no sólo financiero y monetario, sino de lo que vale, de lo que 
es tenido en cuenta en la comunidad (jurídica) en la que vivimos. Y a su vez, el gran espectro -monstruoso y mayoritario- de lo que no cuenta y reclama reconocimiento y redistribución. La cara y la contracara productiva de lo mismo y que entiendo se traduce en un llamado a la imaginación y acción colectivas radicalmente nuevas.

Dos, la necesidad del compromiso político no como mandato sino como un modo de nombrar la apertura hacia la multitud, hacia otros y otras para hacer cosas en común para lo común siempre en disputa. Así, nos dirá Ruiz Resa, reflexionar sobre la enseñanza del derecho nos aboca a pensar en el tipo de comunidades en las que vivimos. Habilitar con insistencia en el espacio áulico de las facultades de derecho la discusión acerca de qué hacemos y cómo nos organizamos (qué normas, qué derecho, para quienes, para qué) respecto de lo común, de aquello que dependemos para vivir como especie, no sólo la tierra, los bosques, el agua, las montañas, incluso los cuidados (terapéuticos y afectivos), sino también el conocimiento y los bienes culturales, es crear la posibilidad de una esperanza (pequeña y potente) que conecta con la que nos propone Benente. Una esperanza, repito, que desplace cada vez el punto de caída de la elipse de la repetición capitalista en el núcleo del derecho.

\section{Jerarquía}

Introducir la reflexión en torno a las jerarquías en la enseñanza del derecho tampoco es una novedad. Jerarquías socioculturales y económicas (de clase, raza, etnia, sexo - genéricas, estatus migratorio...), institucionales (jefes, subordinados; directores, empleados; titulares, jefes de trabajos prácticos; jueces, secretarios...), en las áreas del derecho (el derecho privado en el núcleo; la periferia necesaria del derecho público y, más allá, las otredades filosóficas, sociológicas, políticas); en el sistema jurídico (la norma abstracta y escrita por sobre la norma concreta y viva); en ciertos principios epistemológicos (la objetividad por sobre la subjetividad) y antropológicos (un sujeto que piensa por sobre un sujeto que hace y siente), entre otras ficciones tan reales como una taza de té. Lo cierto es que todo esto acontece en las facultades de 
derecho y en sus aulas como lugares de (re)creación y entrenamiento del personal jurídico.

Bien podemos decir que donde hay jerarquía hay expectativa de obediencia impulsada por mitologías de autoridad. Se obedece por cientos de razones que encontramos analizadas y reunidas en bibliotecas de textos. Pero también donde hay jerarquía hay revuelta, es decir, gente revoltosa que no obedece o no obedece del todo, o al todo. Primer punto a favor de un optimismo situado y encarnado.

Luego, no hay jerarquía que se sostenga sino a la fuerza de las creencias autoritativas (en la ley, en la costumbre, en dios, en las armas). Pero a su vez no hay fuerza -por definición- que no produzca otra exactamente contraria, incluso mayor. La fuerza, ya lo sabemos y leímos entre la gente post (van las gracias), no tiene contenido per se: es pura relación normativa. Y hay un plus: el derrame de fuerzas. Fuerzas que aparecen de otros lados, insospechados, contingentes, imprevistos, hechas de material arcaico y nuevo que rompen la lógica del dos y son un llamado libertario a la emancipación subjetiva y comunitaria. Segundo punto a favor de un optimismo situado y encarnado.

Si tuviera que usar una metáfora para una esperanza radical diría que está en las plantas y en las flores que crecen en las grietas. Construir esa posibilidad en las aulas (en todas, incluidas las del derecho) significa provocar la necesidad de pensar en nombre propio la comunidad.

\section{Androcentrismo}

La enseñanza autoritativa tiene la expectativa de la norma y la técnica limpia y pura, del orden y la disciplina, del control (de conductas, cuerpos, emociones). Tiene la expectativa de lucirse desnuda (neutral, abstracta, ¿les suena?). Lo cierto es que no hay educación (jurídica) que no sea sin experiencia de la vida política. Y la política está vestida de un pastiche de prendas. He aquí el asunto. El juez, el docente, el legislador, el abogado, el rector, el fiscal, no están desnudos. Pero no son sólo las prendas. Es la arquitectura del derecho en donde juegan estos actores (y actoras, claro está) la que también es parte de este pastiche: 
su material, sus pilares, de lo que está fabricada. Y aquí vamos al meollo de una cuestión fundamental -literalmente- de esa arquitectura y que introduce Costa: la condición inherentemente androcéntrica del Derecho. Visto y asumido este punto (que sólo la necesidad puede no ver), una pregunta posible es ¿qué hacemos? A esta altura de la vida y de esta presentación, no se me ocurre más que el volver, cada vez, todos lo días, a (des)pensar el derecho a través de la nutrición de los feminismos jurídicos de izquierda y de otras inspiraciones libertarias. Revisar toda su arquitectura, desvelar esas grandes ficciones que lo sostienen y ver qué (nos) pasa. Destrozar la noción de sujeto de derecho abstracto y asumir un sujeto híbrido; resignificar o abandonar -como más les guste- las dicotomías heteronormadas entre lo público y lo privado, lo reproductivo y lo productivo y crear derecho en las fronteras; abrir las nociones de trabajo y de economía en el derecho restringidas al mercado monetario y financiero, éstas entre tantas acciones jurídicas posibles (sí: iposibles!).

Y así quizás en la insistencia homeopática vaya germinando algo que cotidianamente desintegre el orden desigual, jerárquico y androcéntrico del derecho en el que nacemos, vivimos y morimos.

\section{Un 1lamado: ¡Libertad!}

Todo principio de organización de lo que se percibe disperso, en general, supone un cierto proceso de agrupación reglada que tiene efectos: lo produce ordenado y procura mantenerlo. Así, la naturaleza del derecho es conservadora, pero -y esta es la buena noticia- también es dispersa. El derecho se conserva y se ahueca en el movimiento constante de creación en sus instituciones, a través de sus funcionarios(as) y en lo que la gente (docentes, alumnado, ciudadanía, trabajadores/ as) hace con la norma. Por lo tanto, el efecto de la normalización no es unidireccional. La norma tiene pretensión de estabilidad. Lo disperso tiene pulsión creativa. En ese juego entre la estabilidad y la creatividad oscila el derecho. El asunto es que habitualmente el énfasis en las aulas (como efecto de lo que ocurre en la sociedad) está puesto en lo que 
conserva y no en lo que crea. De allí que la experiencia educativa, en especial en las aulas del derecho, sea enfáticamente conservadora. Por fortuna de la física, en el mundo (jurídico) donde hay sombras, hay luces. Y entonces aparecen cierto optimismo situado y encarnado, las esperanzas, la imaginación y acción colectiva, las resistencias feministas, libertarias y diversas, todo esto y tanto más.

En fin, la instrucción es como la libertad: no se da, se toma (merci Jacotot): ja tomar el derecho!

Abro la puerta y que siga la discusión.

Cálidamente, R. L. 